\title{
INCORPORAÇÃO DE EXTRATO DE ALECRIM EM MEMBRANAS DE ALGINATO E QUITOSANA
}

\author{
V. G. TOMAZ e A. M. MORAES \\ Universidade Estadual de Campinas, Faculdade de Engenharia Química, \\ Departamento de Engenharia de Materiais e de Bioprocessos \\ E-mail para contato: ammoraes@feq.unicamp.br
}

\begin{abstract}
RESUMO - Este trabalho teve por proposta preparar um extrato de alecrim e analisar a factibilidade de sua incorporação em membranas de quitosana-alginato, com a finalidade de estudar a aplicabilidade destes dispositivos como agentes de liberação controlada de extratos vegetais com propriedades microbicidas e antiinflamatórias. $\mathrm{O}$ extrato de alecrim foi obtido por sua exposição a etanol e as membranas foram preparadas por complexação dos polissacarídeos. $\mathrm{O}$ extrato foi avaliado quanto à atividade antioxidante com o uso do radical ABTS e sua incorporação às membranas foi feita por impregnação. Membranas incorporando ou não o extrato foram avaliadas quanto à morfologia de superfície e da secção transversal através de microscopia eletrônica de varredura (MEV) e à eficiência de incorporação do extrato de alecrim. Os resultados obtidos mostraram que a incorporação de extrato de alecrim nas membranas é factível, ocorrendo na forma de depósitos na superfície do material, e a eficiência do processo é elevada.
\end{abstract}

\section{INTRODUÇÃO}

Quitosana e alginato são polissacarídeos muito explorados atualmente na produção de materiais de uso terapêutico devido a uma série de propriedades, incluindo, mas não se limitando, sua bioatividade, abundância e baixo impacto ambiental. Membranas produzidas a partir desses compostos proporcionam um ambiente que estimula a recuperação da lesão devido à sua capacidade de intumescer com soluções salinas, mantendo-a limpa, úmida e protegida, além de serem flexíveis e apresentarem elevada biocompatibilidade (Wang et al., 2002).

Melhorias na performance de membranas deste tipo vêm sendo propostas, como a incorporação de compostos com atividade biológica adicional, destacando-se agentes microbicidas e antiinflamatórios, analgésicos, hormônios e compostos extraídos de plantas. Extratos de plantas como o alecrim são usados em muitos países no tratamento de vários tipos de enfermidade. No caso específico de extratos de alecrim, os efeitos terapêuticos são atribuídos à presença de flavonóides, ácidos fenólicos e diterpenos fenólicos, em especial o ácido carnósico, o carnosol, o ácido rosmarínico e o rosmanol (Justo et al., 2008).

Assim, este trabalho teve por objetivo analisar a factibilidade de incorporação de 
extrato alcoólico de alecrim em membranas de alginato e quitosana por impregnação, analisando-se a eficiência de incorporação e o efeito da presença do extrato na morfologia do material obtido, visando-se especificamente sua aplicação como curativo para lesões de pele.

\section{ATIVIDADES EXPERIMENTAIS}

\subsection{Obtenção do Extrato de Alecrim}

O extrato de alecrim foi preparado com alecrim orgânico (Instituto Agroflorestal Bernardo Hakvoort de Turvo, PR) seco em dessecador por $24 \mathrm{~h}$. Em frasco protegido da luz, adicionaram-se $50 \mathrm{ml}$ de etanol absoluto a $5 \mathrm{~g}$ de alecrim seco. $\mathrm{O}$ material foi colocado em estufa a $50^{\circ} \mathrm{C}$ com agitação de $75 \mathrm{rpm}$ por $3 \mathrm{~h}$. A solução obtida foi filtrada a vácuo com papel de filtro e, em seguida, com membranas de policarbonato.

\subsection{Preparação das Membranas e Incorporação do Extrato de Alecrim}

Para a obtenção das membranas, segundo a metodologia descrita por Bueno e Moraes (2011), $90 \mathrm{~mL}$ de solução de quitosana a 1\% (m/v) em ácido acético a $2 \%(\mathrm{~m} / \mathrm{v})$ foram adicionados a $180 \mathrm{~mL}$ de solução de alginato a $0,5 \%(\mathrm{~m} / \mathrm{v})$ por meio de uma bomba peristáltica (Minipuls 3, Gilson), a uma vazão de $200 \mathrm{~mL} / \mathrm{h}$, em um vaso de aço inoxidável encamisado com temperatura de $25^{\circ} \mathrm{C}$ (banho ultratermostático Q-214M2, Quimis) e agitado a $500 \mathrm{rpm}$ (agitador mecânico Q-251D, Quimis). Ao término da mistura, a taxa de agitação foi aumentada para $1000 \mathrm{rpm}$ e assim mantida por mais 10 minutos. A seguir, foi adicionado $\mathrm{NaOH}$ a $1 \mathrm{M}$ para elevar o $\mathrm{pH}$ a aproximadamente 5,3, mantendo-se a agitação do sistema por mais 10 minutos. Por fim, foram adicionados $3,6 \mathrm{~mL}$ de solução de $\mathrm{CaCl}_{2}$ a $2 \%$ e o sistema permaneceu sob agitação por mais 10 minutos. A mistura foi dividida igualmente em termos mássicos em duas placas de Petri de poliestireno de $15 \mathrm{~cm}$ de diâmetro e levada à estufa com circulação de ar (410D, Nova Ética) a $37^{\circ} \mathrm{C}$ até a secagem do material. Em seguida, cada membrana foi imersa por 30 minutos em $150 \mathrm{~mL}$ de $\mathrm{CaC}_{12}$ a $2 \%$ e, na sequência, lavada com água destilada. A secagem final foi realizada em temperatura ambiente por cerca de 24 horas, sendo as bordas das membranas presas para evitar encolhimento.

Para incorporar o extrato às membranas de quitosana e alginato, amostras com dimensões distintas $(2 \mathrm{~cm} \times 2 \mathrm{~cm}$ e $2,5 \times 2,5 \mathrm{~cm})$ foram imersas em $2 \mathrm{~mL}$ de extrato e colocadas em estufa a $37^{\circ} \mathrm{C}$ por $24 \mathrm{~h}$ para a secagem do etanol. Paralelamente, as membranas foram imersas em etanol somente, visando determinar seu intumescimento neste solvente e também se o mesmo não afetaria a estabilidade das membranas.

\subsection{Caracterização do Extrato de Alecrim e das Membranas}

A atividade antioxidante do extrato obtido foi medida segundo a metodologia descrita por Re et al. (1999), a partir da descolorização do radical ABTS ${ }^{\bullet+}$. Para tal, preparou-se uma solução de $\mathrm{ABTS}^{\bullet+}$ com absorbância em torno de 0,7 a $714 \mathrm{~nm}$. Adicionou-se Trolox até que fossem obtidas soluções com concentrações $0,3,6,9$ e $12 \mu \mathrm{M}$ do composto. A absorbância de cada solução foi medida imediatamente e 5 min após a mistura. Com esses valores, construiuse uma curva de referência relacionando a porcentagem de redução do radical à concentração de Trolox, como mostra a Equação 1, onde R é a redução percentual, $\mathrm{ABS}_{\mathrm{f}}$ é a absorbância da 


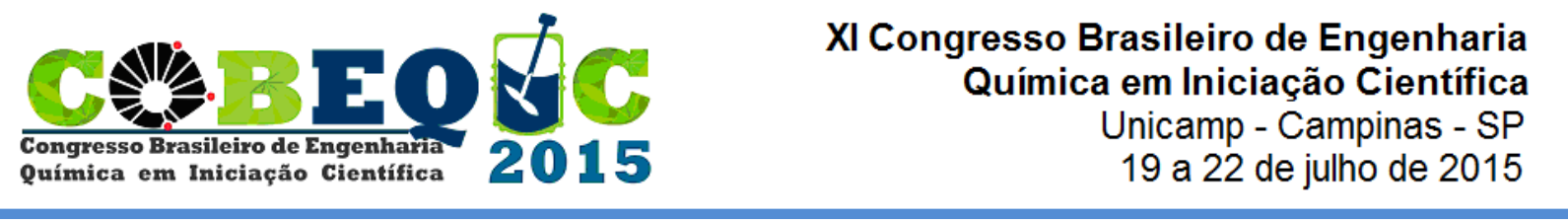

solução após 5 minutos e $\mathrm{ABS}_{\mathrm{i}}$ a absorbância inicial:

$$
R=\left(1-\frac{A B S_{f}}{A B S_{i}}\right) 100
$$

Procedimento semelhante foi realizado com o extrato, mas a concentração usada foi de 10 $\mathrm{g} / \mathrm{L}$. Com o valor de $\mathrm{R}$ da solução com extrato, determinou-se a atividade antioxidante em TEAC (Trolox Equivalent Antioxidant Activity), que é a concentração de extrato equivalente à de Trolox necessária para uma dada diminuição do valor de absorbância da solução causado pela redução do radical. Esses valores são obtidos localizando, na curva de referência, a concentração de Trolox que corresponde ao valor obtido de R.

O intumescimento de membranas de $6 \times 1 \mathrm{~cm}^{2}$ secas expostas por $24 \mathrm{~h}$ a $10 \mathrm{~mL}$ de etanol e sua estabilidade com relação à perda de massa foram analisados por gravimetria.

A morfologia da superfície e da secção transversal das membranas foi avaliada por microscopia eletrônica de varredura (MEV, LEO Electron Microscopy, modelo Leo 440i), armazenando-se antes as amostras em dessecador por $24 \mathrm{~h}$ e metalizando-as com ouro.

A eficiência de incorporação $(\varepsilon)$ do extrato de alecrim foi determinada por gravimetria, avaliando-se a massa das membranas secas antes $\left(M_{s}\right)$ e após a exposição ao extrato etanólico $\left(M_{i n c}\right)$, assim como a massa total de material não volátil $\left(M_{n v}\right)$ extraído do alecrim inicialmente em contato com as membranas, estimada por espectrofotometria de absorção de luz a $280 \mathrm{~nm}$. A Equação 2 foi utilizada para o cálculo de $\varepsilon$.

$$
\varepsilon=\frac{M_{\text {inc }}-M_{s}}{M_{n v}} x 100
$$

\section{RESULTADOS E DISCUSSÃO}

\subsection{Atividade Antioxidante do Extrato Obtido}

O extrato obtido, um produto viscoso de coloração amarelada, teve sua atividade antioxidante analisada pela capacidade de captura do radical ABTS $^{\bullet+}$, expressa em equivalentes Trolox (antioxidante de referência). Para a amostra de extrato de alecrim com concentração de $10 \mathrm{~g} / \mathrm{L}$, observou-se uma redução média de $1,6 \pm 0,4 \%$, resultando em um valor médio em termos de TEAC de $0,04 \pm 0,01 \mu \mathrm{mol} / \mathrm{g}$ de extrato.

Notou-se que o produto obtido por extração etanólica apresentou baixa atividade antioxidante, ao contrário do esperado. Diversos motivos, como a baixa seletividade do processo de extração etanólica, a elevada diluição do extrato e a temperatura relativamente elevada atingida durante o processo podem ter acelerado a degradação dos antioxidantes.

\subsection{Intumescimento e Estabilidade das Membranas Expostas a Etanol}

A imersão das membranas secas em etanol indicou que não ocorre intumescimento na presença desse solvente e que o etanol interage muito fracamente com a membrana. Após a 
secagem, detectou-se que ocorre perda de massa de $5 \pm 1 \%$ em decorrência da exposição ao etanol. Esta análise indicou que embora as membranas mostrem-se estáveis ao solvente, o etanol, não intumescendo a membrana, limita o transporte de massa para o seu interior, o que levaria a uma incorporação apenas superficial. Essa propriedade é útil para incorporarem-se materiais sem alterar propriedades químicas e mecânicas da matriz estrutural da membrana, porém reduziria o controle sobre sua liberação - no caso de fármacos que devem ser liberados aos poucos, este método talvez não se prove o melhor.

\subsection{Morfologia das Membranas Incorporando ou não o Extrato}

A análise da morfologia de superfície e da secção de fratura transversal das membranas expostas somente ao solvente do extrato (etanol) por MEV, mostrada na Figura 1a, revelou uma superfície bastante uniforme e com poucas rugosidades. Já as imagens obtidas das membranas expostas ao extrato, indicadas na Figua 1b, mostram que este não parece não penetrar na matriz da membrana, apenas depositando-se sobre sua superfície, corroborando os resultados esperados com base na análise do intumescimento das membranas em etanol. Ambas as matrizes apresentam estruturas lamelares.

Figura 1- Imagens do aspecto morfológico típico avaliado por MEV da superfície das membranas expostas somente a etanol (a) ou após a incorporação do extrato de alecrim (b).
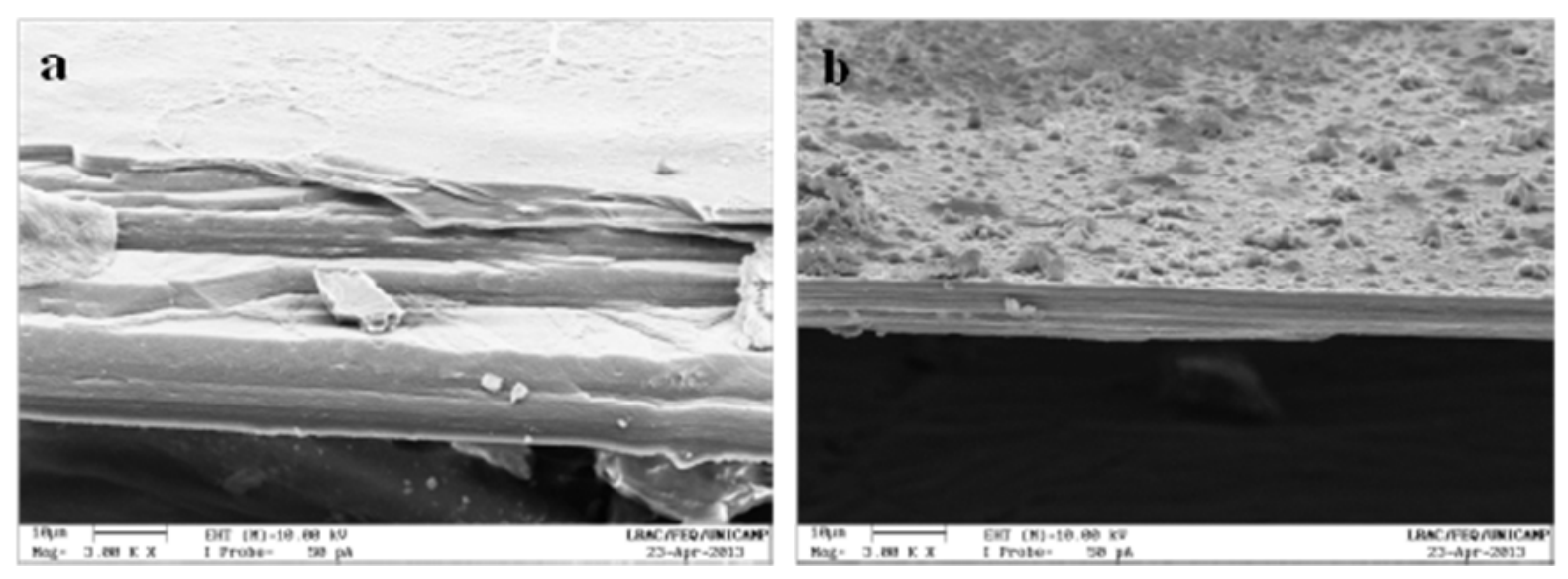

A análise morfológica mais detalhada revelou que a deposição pode acontecer de duas maneiras distintas: a primeira em gotículas que cobrem quase integralmente a superfície da membrana e a segunda na forma de agregados reticulares de forma aproximadamente esférica cujo tamanho varia de 6 a $10 \mu \mathrm{m}$ distribuídos espaçadamente. O aspecto dos depósitos pode ser observado na Figura 2. A hipótese levantada acerca da formação dos dois tipos de deposição é de que as gotículas são depositadas através simplesmente da ação gravitacional no lado superior da membrana; os agregados, por outro lado, são formados no lado inferior da membrana durante a imersão - situação em que a ação gravitacional contribui para a não aderência das gotículas - através de um mecanismo de coalescência e crescimento do depósito, o que explicaria a formação dos retículos.

\subsection{Eficiência de Incorporação do Extrato de Alecrim nas Membranas}

Conforme já mencionado, as micrografias indicam que o extrato apenas se deposita na 
superfície das membranas. Desta forma, a capacidade de incorporação estaria, supostamente, diretamente associada à área superficial da amostra. Na Tabela 1 estão indicados os resultados obtidos na determinação da eficiência de incorporação do extrato, estimando-se adicionalmente a massa de extrato depositada por área de membrana (topo e base), $\delta$.

Nota-se que a eficiência de incorporação foi bastante satisfatória nos dois casos, principalmente considerando-se que o extrato tem natureza hidrofóbica e as membranas, hidrofílica. Como o principal mecanismo de incorporação do extrato é através da deposição, a eficiência do processo está, de fato, diretamente relacionada à fração da secção transversal do recipiente onde ocorre a incorporação ocupada pela membrana.

Figura 2 - Imagens de microscopia eletrônica de varredura da superfícia das membranas após a incorporação do extrato de alecrim, evidenciando as gotículas esféricas (a

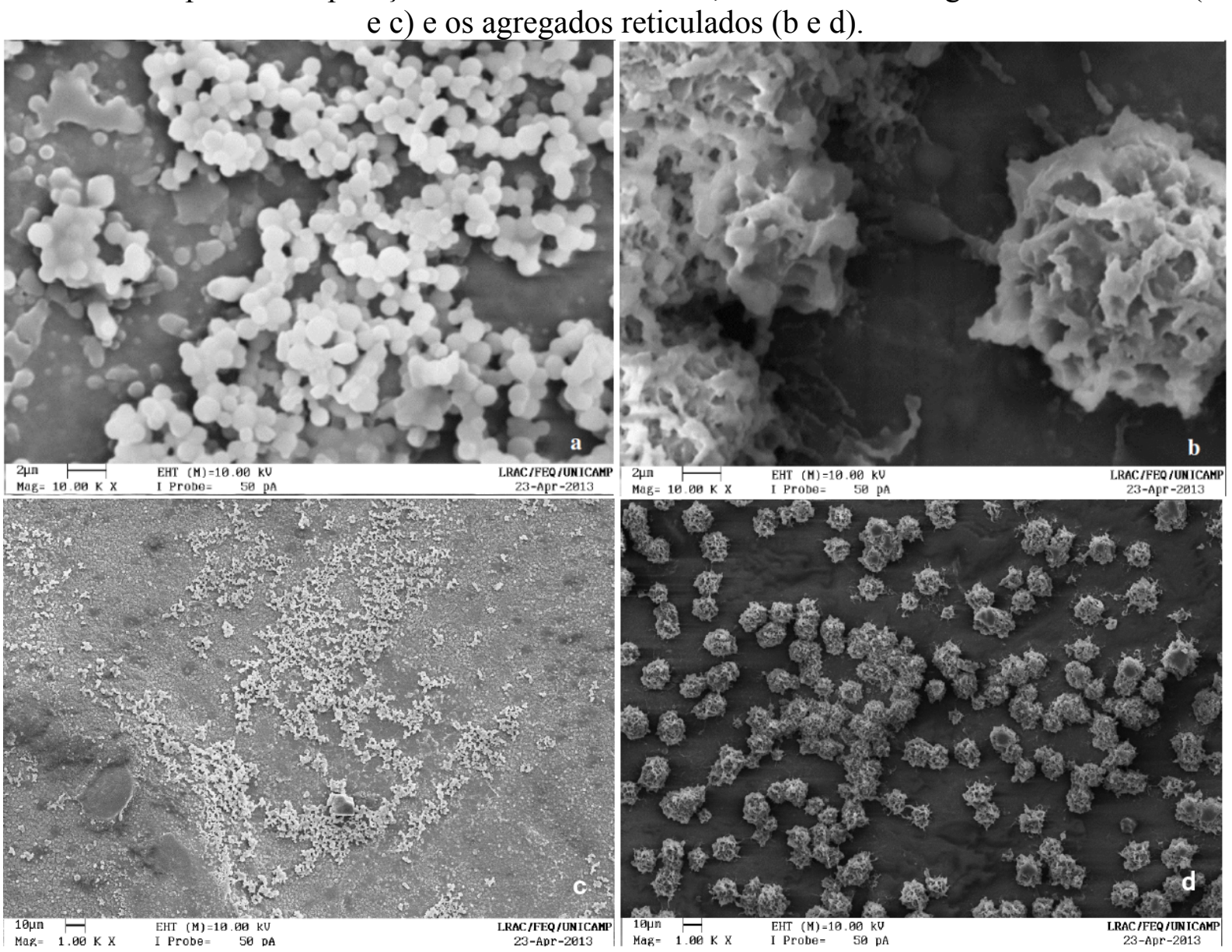

Tabela 1 - Incorporação do extrato de alecrim em membranas de dimensões distintas.

\begin{tabular}{cccccc}
\hline $\begin{array}{c}\text { Área da amostra } \\
\left(\mathbf{c m}^{\mathbf{2}} \mathbf{\times} \mathbf{~ c m}^{\mathbf{2}}\right)\end{array}$ & $\boldsymbol{M}_{\boldsymbol{n} \boldsymbol{v}}(\mathbf{m g})$ & $\boldsymbol{M}_{\boldsymbol{s}}(\mathbf{m g})$ & $\boldsymbol{M}_{\boldsymbol{i n c}}(\mathbf{m g})$ & $\boldsymbol{\varepsilon}(\boldsymbol{\%})$ & $\boldsymbol{\delta}\left(\mathbf{m g} / \mathbf{c m}^{\mathbf{2}}\right)$ \\
\hline $\mathbf{2} \mathbf{2}$ & $17,37 \pm 0,07$ & $17,73 \pm 1,12$ & $24,07 \pm 1,56$ & $36,55 \pm 7,00$ & $0,79 \pm 0,15$ \\
$\mathbf{2 , 5} \mathbf{2} \mathbf{2 , 5}$ & $18,82 \pm 0,23$ & $27,15 \pm 3,63$ & $36,73 \pm 4,41$ & $50,89 \pm 5,97$ & $0,766 \pm 0,09$ \\
\hline
\end{tabular}


Valores maiores não foram alcançados porque a matriz polissacarídica não sofre intumescimento na presença de etanol, o que dificulta a difusão dos componentes do extrato para o interior da matriz. A eficiência de incorporação das membranas com $2,5 \mathrm{~cm}$ de lado, entretanto, é cerca de $36,55 \%$ maior que a das membranas com $2 \mathrm{~cm}$ de lado, mas como área superficial é $56 \%$ maior, a relação de massa de extrato por $\mathrm{cm}^{2}$ de ambos os tipos de amostras, $\delta$, é muito próxima, conforme esperado de uma incorporação superficial.

A melhoria da incorporação pode ser explorada utilizando-se outras técnicas de contato do extrato com as membranas (Abdollahi et al., 2012; Albertini et al., 2013) ou mesmo pela modificação da composição da matriz polimérica, aumentando-se sua hidrofobicidade.

\section{CONCLUSÃO}

Este trabalho mostrou que é possível incorporar extrato de alecrim obtido em etanol por impregnação em membranas de quitosana e alginato. As membranas são de confecção simples e pouco custosa e o extrato de alecrim se deposita com alta eficiência de incorporação na forma de gotículas ou de material agregado em sua superfície, entretanto, a a atividade antioxidante do extrato de obtido é baixa. Para a continuidade deste trabalho, recomenda-se explorar outros métodos de extração (como a mediada por fluidos em condições supercríticas), visando alcançar extratos com maior atividade antioxidante, outras formas de incorporação e de formulação das membranas, assim como estudar a cinética de liberação e a atividade biológica em si do conjunto membrana-extrato.

\section{AGRADECIMENTOS}

Os autores deste trabalho agradecem o apoio da FAPESP e do CNPq.

\section{REFERÊNCIAS}

ABDOLAHIA, M., REZAEIA, M. \& FARZIB, G. A novel active bionanocomposite film incorporating rosemary essential oil and nanoclay into chitosan. J. of Food Eng., p. 343350, 2012.

ALBERTINIi, B. et al. Novel multifunctional platforms for potential treatment of cutaneous wounds: Development and in vitro characterization. Int. J. of Pharmac., Volume 440, p. 238-249, 2013.

BUENO, C. e MORAES, A. M. Development of porous lamellar chitosan-alginate membranes: Effect of different surfactants on biomaterial properties. J. Ap. Poly. Sci., Volume 122, p. 624-631, 2011.

JUSTO, O. R.; MORAES, A. M.; BARRETO, G. P. M.; MERCADANTE, A. Z.; ROSA, P. T. V. Avaliação do potencial antioxidante de extratos ativos de plantas obtidos por extração com fluido supercrítico. Quím. Nova, v. 31, p.1699-1705, 2008.

RE, R. et al. Antioxidant activity applying an imroved ABTS racical cation decolorization assay. Free Racial Bio. \& Med., p. 1231-1237, 1999.

WANG, L.; KHOR, E.; WEE, A.; LIM, L. Y. Chitosan-alginate PEC membrane as a wound dressing: Assessment of incisional wound healing. J. Biomed. Mater. Res.,v. 63(5), p. 610-8, 2002. 